\title{
Late onset heterozygous ornithine transcarbamylase deficiency mimicking complex partial status epilepticus
}

\author{
M D Bogdanovic, D Kidd, A Briddon, J S Duncan, J M Land
}

\begin{abstract}
A 57 year old woman with post-traumatic complex partial seizures was admitted because of recurrent episodes of altered mental state over the preceding 4 years, each lasting up to 5 days. There was a history of dietary protein intolerance since childhood and two of her daughters had died in the neonatal period from unexplained encephalopathies. In hospital she developed fluctuating confusion, amnesia, and sudden episodes of unresponsiveness. An EEG was consistent with complex partial status epilepticus but there was no response to benzodiazepines. Nasogastric feeding and sodium valproate were given and shortly afterwards she lapsed into a deep coma. Blood ammonia and urinary orotate were raised, and genetic testing confirmed that she was a carrier of a mutation in exon 3 of the ornithine transcarbamylase gene ( $C$ to $T$ at position 92). Treatment with protein restriction, carnitine, and sodium phenylbutyrate led to a full recovery over a period of 3 months. To our knowledge this is the oldest age of onset yet described in a manifesting carrier. She is the fifth patient with heterozygous ornithine transcarbamylase deficiency reported to have had a severe reaction to sodium valproate. Hyperammonaemic encephalopathy should be considered in patients of any age who experience fluctuating confusion. (F Neurol Neurosurg Psychiatry 2000;69:813-815)
\end{abstract}

Keywords: epilepsy; ornithine transcarbamylase deficiency; ammonia

The National Hospital for Neurology and Neurosurgery, Queen

Square, London WC1N 3BG, UK M D Bogdanovic

D Kidd

A Briddon

J S Duncan

J M Land

Correspondence to: Dr J M Land

jland@ion.ucl.ac.uk

Received 15 March 2000 and in final form 25 July 2000 Accepted 7 August 2000
Symptoms may be non-specific (for example, malaise, weakness, headache) or severe and life threatening (for example, seizures, coma, permanent neurological deficits). Chronic encephalopathy may cause progressive neurological deterioration. Misdiagnosis and diagnostic delays are common. ${ }^{5}$ Known precipitants of encephalopathy include parturition, ${ }^{46}$ catabolic states due to trauma or infection, ${ }^{4}$ concurrent liver disease, ${ }^{7}$ high protein intakefor example, due to parenteral nutrition ${ }^{8}$ - and valproate therapy. ${ }^{9-13}$

We describe a middle aged woman with post-traumatic epilepsy who also had episodes of altered mental state misdiagnosed as complex partial status epilepticus. Valproate therapy and supplemental feeding during one of these episodes precipitated deep coma, thus suggesting the diagnosis.

\section{Case report}

A 57 year old woman was admitted for optimisation of therapy for a presumed posttraumatic partial seizure disorder.

At the age of 18 she fractured her skull in a motorcycle accident and was in a coma for 6 days. When she was 28 she began to have infrequent episodes of loss of consciousness preceded briefly by a "rushing" sensation in the head. She would sink to the ground and lie motionless before recovering promptly. No tonic-clonic seizures occurred. An EEG showed slowing over the left temporal region without epileptiform features. She was unable to tolerate phenobarbital and phenytoin, but was successfully treated with clonazepam. Attacks ceased at the age of 38 .

At the age of 53 she began to have infrequent attacks characterised by an epigastric rising sensation, then blankness and fiddling movements of the hands lasting a few minutes, then a rapid recovery. A few months later she was admitted to hospital unconscious, having had fluctuating confusion over a few days. Herpes simplex encephalitis was suspected and she was treated with aciclovir. She made a good recovery, but complained of listlessness in the afternoons and headaches. Over the next 4 years there were eight similar episodes lasting up to 5 days: there was fluctuating confusion and amnesia punctuated by attacks of sudden loss of consciousness, with a gradual decline in responsiveness and oral intake followed by a 


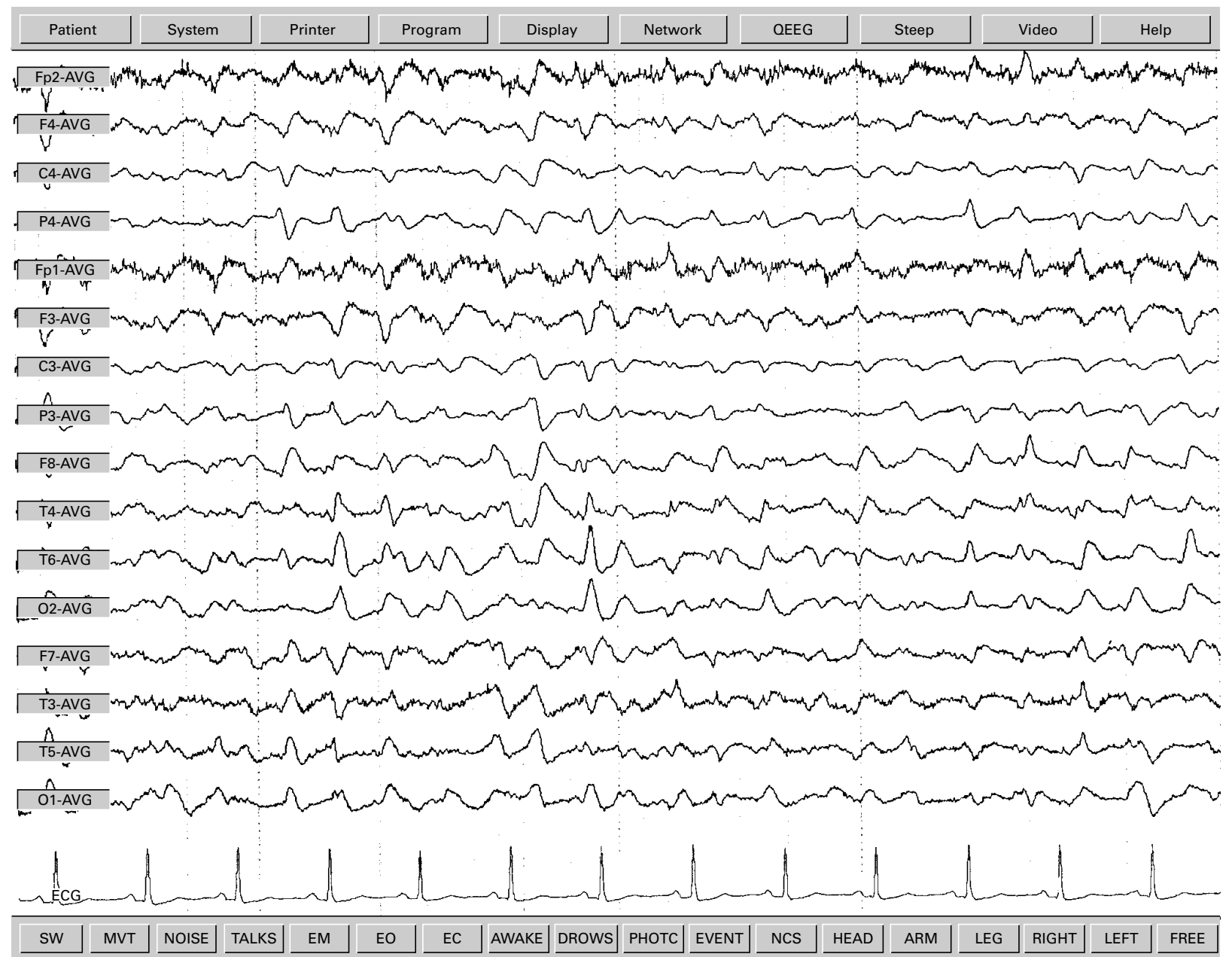

EEG recorded in the resting state when the patient was drowsy but responsive. The record is abnormal and shows a generalised, irregular, medium to large amplitude 3-5 cps activity intermixed with frequent bilateral sharp waves which are more prominent over the anterior regions.

spontaneous recovery. On one occasion this had been associated with a respiratory infection and tracheal intubation and ventilation was required.

Brain MRI showed cortical damage in the right frontal and temporal regions as well as mild generalised atrophy. Phenytoin and vigabatrin were tried without effect and she was maintained on carbamazepine, lamotrigine, and clonazepam.

She was admitted for optimisation of antiepileptic therapy but before any changes were made she began to have frequent episodes of confused speech with marked perseveration and amnesia for events. She was disorientated in time and place. An EEG showed continuous semirhythmic 3-5 cps activity with sharp components (figure) and a diagnosis of complex partial status epilepticus was made. Treatment with clobazam and lorazepam was ineffective.

Over the next few days she improved but remained confused and was eating and drinking very little; a nasogastric tube was passed and a standard feed started ( $40 \mathrm{~g}$ protein/day). By day 12 she had failed to recover and valproate was given: she received a total of $5 \mathrm{~g}$ over 7 days. There was a marked deterioration in her condition and by day 18 she was unresponsive to painful stimuli and unable to protect her airway. Tracheal intubation was performed. Blood ammonia was measured at $165 \mu \mathrm{mol} / 1$ (normal $12-47 \mu \mathrm{mol} / \mathrm{l}$ ) and urinary orotate was significantly increased at $37 \mu \mathrm{mol} /$ mmol creatinine (normal $\leqslant 15 \mu \mathrm{mol} / \mathrm{mmol}$ ). Blood amino acid profile assessed by ion exchange chromatography showed raised glutamine, reduced arginine, and normal concentrations of citrulline. No arginosuccinic acid was detected. These results were consistent with a diagnosis of ornithine carbamoyltransferase deficiency. Feeding was suspended and she received intravenous carnitine and nasogastric sodium phenylbutyrate. She remained unresponsive to painful stimuli for 7 days before steadily improving. Blood ammonia peaked at $380 \mu \mathrm{mol} / 1$, but her clinical condition did not follow the level closely. Swallowing function remained impaired, and a percutaneous gastrostomy tube was required. She was discharged on day 82 with no neurological abnormalities except slight impairment of swallowing, which has since resolved. At follow up 1 year later she had remained well, with no further episodes of prolonged loss of awareness, but occasional brief partial seizures.

On further questioning it transpired that two of her three daughters had died in the neonatal period of an undiagnosed encephalopathy. No other family members have had unexplained 
illnesses and her only other offspring (a female) is not a carrier. For most of her life she had avoided eating meat and dairy products because they made her feel unwell.

Genetic analysis was performed using the following strategy: deletion of one copy of the ornithine carbamoyltransferase gene was excluded by dosage analysis, and then each exon was examined by single strand conformation polymorphism. This suggested an abnormality in exon 3, which was then amplified by polymerase chain reaction (PCR) and sequenced. $\mathrm{C}$ to $\mathrm{T}$ point mutation was found at position 92 , which results in a change from an arginine to a stop codon. This mutation has previously been reported, causing a severe illness in a male neonate. ${ }^{114}$ Indeed, residue 92 is thought to form part of the substrate binding site. A Taq 1 restriction site is also altered, and this digest was performed on the PCR product to confirm the sequencing result.

\section{Discussion}

Three kinds of attack were seen in this patient. As a result of her head injury, she experienced complex partial seizures, probably unrelated to her urea cycle defect. Beginning in middle life, she had mild and apparently unprovoked episodes of hyperammonaemia causing fluctuating confusion over several days. These were misdiagnosed as recurrent complex partial status epilepticus. Thirdly, when one such episode happened to occur while she was in hospital, a prolonged episode of deep coma resulted from valproate administration and nasogastric feeding. Her partial seizures have continued despite effective treatment of her hyperammonaemia.

Carrier status is not necessarily benign in ornithine carbamoyltransferase deficiency. Batshaw et al identified 61 heterozygotes from 17 ornithine carbamoyltransferase deficient kindreds and found that $11(18 \%)$ had had encephalopathic episodes. ${ }^{3}$ Nine of these 11 died during such episodes, although in several cases the diagnosis was made retrospectively. Fries et al described three manifesting carriers who presented in childhood ${ }^{15}$ two of whom had significant developmental delay. Seizures are often seen during hyperammonaemic encephalopathy, but epilepsy is not found in asymptomatic carriers: Maestri et al identified no women with epilepsy among 79 ostensibly healthy carriers from 89 families compared with one among 96 non-carriers from the same kindreds. ${ }^{4}$ Variation in severity between kindreds is in part due to the different effects of different molecular defects in the enzyme (over 160 have been described). Variation in severity between females in the same kindred is thought mainly to be due to chance, which governs the pattern of X chromosome inactivation.

Age of presentation is very variable in manifesting carriers. In the worst affected cases, presentation occurs in the neonatal period. It is likely that the two daughters of our patient who died as neonates were severely affected carriers. However, presentations have been described even in middle life. Gilchrist et al report two cases of women aged 36 and 38 presenting with encephalopathy. ${ }^{7}$ In one case alcohol misuse and in the other chronic cytomegalovirus infection were thought to have been precipitants. Brusilow and Horwich reported on a 44 year old man who died during his first episode of hyperammonaemia. ${ }^{1}$ Our case may be the oldest reported presentation of heterozygous OTC deficiency. To our knowledge it is the fifth reported female with ornithine carbamoyltransferase deficiency who has had a severe reaction to sodium valproate. We found no evidence to support occult liver disease as a precipitating factor, but on a few occasions in the years before presentation mildly raised random blood glucose concentrations had been found. Adult onset diabetes may be considered to be uncontrolled gluconeogenesis, a process that requires ammonium excretion. It is possible this was a contributing factor in her presentation.

We conclude that this diagnosis should be considered in a patient of any age who has prolonged episodes of altered mental state, particularly if the EEG is consistent with a metabolic encephalopathy. Great care should be exercised in the use of supplemental feeding and valproate therapy in this situation. Enquiry about protein avoidance and unexplained neonatal deaths in the family may be of diagnostic value. Equally we would advise the routine assessment of blood ammonia concentrations in patients such as the one described here.

We thank the following people for their help with the preparation of this report: Ann Baker from the EEG department at the National hospital; Treena Cranston and Sally Genet from the clinical molecular genetics laboratory at the Institute of Child Health.

1 Brusilow SW, Horwich AL. Urea cycle enzymes. In: Scriver $\mathrm{CR}$, et al, eds. The inherited basis of metabolic disease. New York: McGraw-Hill, 1995:1187-221.

2 DiMagno EP, Lowe JE, Snodgrass PJ, et al. Ornithine transcarbamylase deficiency: a cause of bizarre behaviour in a man. N Engl f Med 1986;315:744-7.

3 Batshaw ML, Msall M, Beaudet AL, et al. Risk of serious illness in heterozygotes for ornithine transcarbamylase ness in heterozygotes for ornithine

4 Maestri NE, Lord C, Glynn M, et al. The phenotype of ostensibly healthy women who are carriers for ornithine
transcarbamylase deficiency. Medicine 1998;77:389-97.

transcarbamylase deficiency. Medicine 1998;77:389-97.
5 Rowe PC, Newman SL, Brusilow SW. Natural history of Rowe PC, Newman SL, Brusilow SW. Natural history of
symptomatic partial ornithine transcarbamylase deficiency. N Engl F Med 1986;314:541-7.

6 Arn PH, Hauser ER, Thomas GH, et al. Hyperammonemia in women with a mutation at the ornithine carbamoyltransferase locus. A cause of postpartum coma [see comments]. N Engl f Med 1990;322:1652-5.

7 Gilchrist JM, Coleman RA. Ornithine transcarbamylase deficiency: adult onset of severe symptoms. Ann Intern Med 1987; 106:556-8

8 Felig DM, Brusilow SW, Boyer JL. Hyperammonemic coma due to parenteral nutrition in a woman with heterozygous ornithine transcarbamylase deficiency. Gastroenterology 1995;109:282-4.

9 Oechsner M, Steen C, Sturenburg HJ, et al. Hyperammonaemic encephalopathy after initiation of valproate therapy in unrecognised ornithine transcarbamylase deficiency. $\mathcal{F}$ in unrecognised ornithine transcarbamylase

10 Leao M. Valproate as a cause of hyperammonemia in heterozygotes with ornithine-transcarbamylase deficiency. Neurology 1995;45:593-4.

1 Honeycutt D, Callahan K, Rutledge L, et al. Heterozygote ornithine transcarbamylase deficiency presenting as symptomatic hyperammonemia during initiation of valproate therapy. Neurology 1992;42:666-8.

12 Tokatli A, Coskun T, Cataltepe S, et al. Valproate-induced lethal hyperammonaemic coma in a carrier of ornithine carbamoyltransferase deficiency. F Inher Metab Dis 1991; 14:836-7

13 Kay JD, Hilton-Jones D, Hyman N. Valproate toxicity and ornithine carbamoyltransferase deficiency [letter]. Lancet 1986;ii: $1283-4$

14 Grompe M, Caskey CT, Fenwick RG. Improved molecular diagnostics for ornithine transcarbamylase deficiency. Am $\mathcal{F}$ Hum Genet 1991;48:212-22.

15 Fries MH, Kuller JA, Jurecki E, et al. Prenatal counselling in heterozygotes for ornithine transcarbamylase deficiency. Clin Pediatr 1994;33:525-9. 